\title{
Desempenho e fragmentação da indústria de alta tecnologia do Mercosul
}

\author{
CAMILA DO CARMO HERMIDA \\ ANA PAULA MACEDO DE AVELLAR \\ CLÉSIO LOURENÇO XAVIER \\ MARISA DOS REIS AZEVEDO BOTELHO*
}

\begin{abstract}
RESUME: O objetivo deste artigo é avaliar a real inserção do Mercosul no comércio internacional de manufaturas de alta tecnologia e o grau de evolução ao longo da cadeia tecnológica. A principal contribuição deste artigo é a construção de um indicador de valor adicionado, resultado da diferença entre as exportações de bens finais e as importações de partes e componentes. Tal indicador permite uma análise mais adequada, em termos de saldo comercial, de setores cada vez mais inseridos em processos de fragmentação produtiva. A principal conclusão é de que não há evidências fortes de que tais países estejam avançando para etapas mais a jusante das cadeias de valor nos setores de alta tecnologia, com exceção do setor de aeronaves (especialmente do Brasil).
\end{abstract}

PALAVRAS-CHAVE: alta tecnologia; saldo comercial; fragmentação; valor adicionado; Mercosul.

ABSTRACT: Performance and fragmentation of Mercosur high-tech industry. The objective of this paper is to evaluate the actual insertion of the Mercosur in the international trade of goods with high technology and the degree of progress along the technological chain. The main contribution of this paper is to construct an indicator of value added, results from the difference between exports of final goods and imports of parts and components. This indicator allows a more appropriate analysis in terms of trade balance, of sectors increasingly embedded in processes of production fragmentation. The main conclusion is that there is no strong evidence that such countries are moving towards more downstream stages of the value chains in high technology sectors, except for the aircraft industry (especially Brazil). KEYWORDS: high technology; trade balance; fragmentation; value added; Mercosur. JEL Classification: F13; F14; F15; O14; OJ9.

\footnotetext{
* Respectivamente, Professora substituta do Instituto de Economia da UFU. Doutoranda do Programa de Pós-Graduação em Economia da Universidade Federal de Uberlândia. E-mail: camilachermida@ie. ufu.br; Professora do Instituto de Economia da Universidade Federal de Uberlândia, Pesquisadora FAPEMIG e Bolsista de Produtividade do CNPq. E-mail: anaavellar@ie.ufu.br; Professor do Instituto de Economia da Universidade Federal de Uberlândia, Pesquisador e Bolsista de Produtividade do CNPq. E-mail: clesio@ie.ufu.br; Professora do Instituto de Economia da Universidade Federal de Uberlândia. E-mail: botelhomr@ufu.br. Submetido: 20/junho/2013; Aprovado: 22/agosto/2014.
} 


\section{INTRODUÇÃO}

Nas últimas décadas, o processo de globalização ampliado com a liberalização comercial modificou sobremaneira a natureza e a extensão dos mercados, com firmas vendendo seus produtos finais, partes e componentes, por todo o mundo e para diferentes fases do processo produtivo. Além disso, reduziu os custos de comunicação, transporte e organização institucional entre fronteiras, o que, associado às inovações tecnológicas e à fragmentação do processo produtivo, promoveu o crescimento do volume de mercadorias transacionadas internacionalmente e impulsionou a integração comercial e produtiva entre os países. No entanto, os efeitos expansivos do comércio não se difundiram globalmente, estando concentrados em poucos países e regiões que operam como mercados integrados. Em 2009, apenas três regiões foram responsáveis por aproximadamente $80 \%$ do PIB mundial e dominaram $84 \%$ do comércio global: União Europeia $(41,2 \%)$; Leste Asiático $(29,45)$ e Nafta (EUA, Canadá e México - 13,2\%), enquanto a América Latina apresentou um resultado bastante incipiente $(3,8 \%)^{1}$.

Quando se trata de mercados mais dinâmicos, baseados em produtos com maior intensidade tecnológica e em conhecimento, responsáveis pelo ritmo cada vez maior do comércio internacional, a literatura aponta fortes evidências de que os países em desenvolvimento estão aumentando suas exportações e parcelas de mercado. Contudo, vários trabalhos sugerem que esse desempenho apresenta-se bastante concentrado entre os países do Leste Asiático, e que tal sucesso, em termos de fluxos comerciais e crescimento econômico, está associado à sua especialização produtiva e comercial, na qual processos coordenados de fragmentação da produção contribuíram de forma importante no desenvolvimento de catch-up tecnológico na região (Lall, 2000; Baumann, 2011; Lemoine e Ünal-Kesenci, 2011).

No caso dos países que compõem o Mercado Comum do Sul - Mercosul, Argentina, Brasil, Paraguai, Uruguai e, mais recentemente, Venezuela, predomina-se uma especialização produtiva fortemente baseada nas exportações de produtos primários e de bens manufaturados intensivos em recursos naturais. Tais produtos, pelas suas características técnicas (baixa intensidade de trabalho e processos contínuos de produção) não são, em sua maioria, objeto de fragmentação das etapas produtivas que está na origem das cadeias globais de valor. Ademais, percebe-se um esforço de políticas no sentido de realizar processos de industrialização dos setores de alta tecnologia e de formar cadeias produtivas transacionais que viabilizem um aumento das exportações desses produtos. Entretanto, a necessidade de geração de inovações para o desenvolvimento dos setores de alta tecnologia é fundamental e como tais países não possuem grandes investimentos em Pesquisa \& Desenvolvimento, além de outras atividades de esforço inovativo, durante o processo produtivo grande parte dos componentes desses produtos é importada, o que atinge de forma negativa o saldo da balança comercial desses países.

\footnotetext{
${ }^{1}$ World Bank Data (2010).
} 
Sobre isso, Lall (2000) aponta que aumentos na participação de setores de alta tecnologia nas exportações de países em desenvolvimento pode ser apenas uma espécie de "ilusão estatística", já que tais países tendem a se especializar em setores intensivos em trabalho dentro das indústrias intensivas em tecnologia. Além disso, com a fragmentação produtiva as exportações de produtos de alta tecnologia não indicam, necessariamente, se determinado país domina a base tecnológica do processo produtivo ou apenas realiza a montagem final do produto.

Dessa forma, o objetivo deste artigo é avaliar o grau em que os países do Mercosul vêm evoluindo ao longo da cadeia tecnológica e aumentando o conteúdo doméstico de sua indústria de alta tecnologia e verificar a evolução do comércio intraregional dos setores de alta tecnologia no Mercosul. Será analisado também se tais países estão atuando como meros montadores de bens finais ou se há alguma evidência de que estão se tornando produtores de determinados bens mais intensivos em tecnologia. O artigo está organizado em três seções e uma conclusão. $\mathrm{Na}$ primeira seção, é feito um breve levantamento de contribuições teóricas sobre o processo de fragmentação da produção e da formação de cadeias globais de valor. A segunda seção apresenta um panorama geral do comércio de produtos de alta tecnologia dos países do Mercosul comparativamente a outras economias e da integração comercial entre os países do bloco. E a terceira seção examina a evolução do valor adicionado doméstico de alguns dos setores de alta tecnologia que mais se destacaram nos fluxos de comércio das economias do bloco.

\section{ASPECTOS TEÓRICOS}

Uma questão amplamente debatida por parte da literatura econômica recente é se o que um país produz e exporta tem relevância para seu desenvolvimento econômico. Chenery (1960), Rodrik (2006), Hausmann, Hwang e Rodrik (2007), CEPAL (2008) e Lall (2000) estão entre os que argumentam e apresentam resultados de estudos que apontam que setores industrializados e/ou intensivos em progresso técnico possibilitam maiores oportunidades de crescimento devido ao aumento do potencial de upgrade vertical dentro do setor/produto e de benefícios associados à spillovers de conhecimento e a transbordamentos da tecnologia. Tal constatação e a busca por um aumento da competitividade em setores de maior conteúdo tecnológico pelos países em desenvolvimento têm intensificado os fluxos de produtos intensivos em tecnologia e, por isso, têm sido um dos principais fatores, apontados pela literatura, responsáveis pelo dinamismo da atual configuração do comércio internacional.

Outra parte da literatura econômica argumenta que o aumento dos fluxos de tais produtos resulta, fundamentalmente, da combinação de dois processos inter-relacionados: a fragmentação da produção e a formação de cadeias globais de valor com a consequente integração produtiva das economias.

A fragmentação da produção é originalmente conceituada, nos estudos de organização industrial, como uma combinação de processos produtivos desenvolvidos externamente à firma, que ocorre por meio da divisão da produção em pro- 
cessos e unidades separadas até obter um ou vários produtos finais. No entanto, um fenômeno considerado moderno e de grande importância no cenário atual é a integração de todo o processo produtivo em diferentes locais do mundo, ou seja, a internacionalização da produção (Flôres, 2010).

Devido aos avanços da tecnologia da produção, das inovações em transporte e comunicação, da ampliação da variedade e alcance de serviços oferecidos, das reformas de liberalização com quedas de barreiras comerciais e outros fatores ${ }^{2}$, um número cada vez maior de firmas passou a transferir para outros países partes inteiras da cadeia produtiva, importando os insumos num estágio mais avançado de produção (Feenstra, 1998; Athukorala e Yamashita, 2006; Yeats, 2001). Especialmente para países onde a mão de obra era relativamente mais barata, dado seu encarecimento da mesma nos países desenvolvidos e para países com maior proximidade geográfica, o que exercia o papel das vantagens comparativas ricardianas ao longo do processo de produção.

Tais fatores levaram também a volumosos fluxos de Investimentos Diretos Externos (IDE) ${ }^{3}$ provenientes de grandes empresas multinacionais (EMN) em busca de maior eficiência produtiva com redução de custos de trabalho e exploração de economias de escala, o que influiu sobremaneira na consolidação de redes integradas de produção.

De acordo com Medeiros (2010), a fragmentação da produção, nesses moldes, foi resultado da internacionalização de um novo paradigma industrial a partir dos anos 1970, baseado na desintegração vertical, ou seja, na externalização de atividades. Este novo padrão produtivo expandiu-se rapidamente na economia mundial, sobretudo nas indústrias com alto teor tecnológico, intensivas em trabalho e marcadas por um processo de produção segmentado em distintos e independentes estágios produtivos, como as indústrias eletrônica, automobilística, de informática, de aviação e de brinquedos.

Segundo Dullien (2010), a integração produtiva entre países pode se manifestar, basicamente, de duas formas: cada país pode se especializar na produção de um ou mais bens complementares, nos quais possuam vantagens comparativas; diferentes países podem realizar diferentes estágios (verticais) de produção. Uma integração aos moldes das Vantagens Comparativas pode promover economias de escala em cada um dos países envolvidos, no entanto não contribui para seu desenvolvimento tecnológico ou para uma mudança nos seus padrões de especialização. Um exemplo disso é o caso das indústrias têxteis e de vestuários em economias avançadas, que produzem seus produtos em países em desenvolvimento a fim de se aproveitarem dos custos reduzidos com mão de obra não qualificada, mas mantêm seus setores de P\&D, o design e a distribuição no país sede (Flôres, 2010)4.

\footnotetext{
${ }^{2}$ Não é propósito deste artigo discutir profundamente as causas da fragmentação tanto em nível nacional quanto no nível da firma. Sobre isso, ver: Feenstra (1998); Athukorala e Yamashita (2006).

${ }^{3} \mathrm{O}$ exemplo da China mostra, claramente, a importância de IDE cuidadosamente planejado nos setores de processamento voltados para o mercado externo.

${ }^{4}$ Outro exemplo são as denominadas maquilas na fronteira norte do México, destinadas apenas à
} 
Já quando baseado na fragmentação da produção, Dullien (2010) aponta que há diversos efeitos positivos para o progresso tecnológico e o desenvolvimento da capacidade produtiva da economia, independentemente dos distintos estágios de produção ocorrerem em uma EMN (com IDE em filiais estrangeiras) ou por meio da terceirização (várias empresas) em outros países. Ou seja, a integração pode ocorrer, por vezes, via combinação de dois fenômenos: a fragmentação dos sistemas de produção com a desverticalização das operações industriais e de serviços e a transferência de atividades produtivas para outras regiões ou países (processo multipaís); e a formação de Cadeias Globais de Valor (CGV), com a produção sendo desenvolvida para além dos limites da firma, com fases da produção realizadas por diferentes empresas (processo multifirma).

Estudos como os de Gereffi $(1994,1999)$ analisam as CGVs ${ }^{5}$ como uma inovação organizacional global recente, na qual uma empresa passa a realocar as atividades produtivas para outras firmas, retendo as competências-chave do processo produtivo e difundindo somente as etapas menos relevantes para as demais. De acordo com esses autores, a produção realizada por meio de uma CGV é caracterizada da seguinte forma: no topo da cadeia localiza-se uma empresa fornecedora - líder no segmento, geralmente, advinda de países desenvolvidos. Ela é a responsável por organizar, controlar e desenvolver as cadeias de produção, formadas por suas subsidiárias ou por outras firmas que ficam responsáveis, em conjunto e em diferentes países, pelo desenvolvimento do produto final. Na maior parte das CGVs, o processo de geração de conhecimento e de inovações fica concentrado nessa empresa líder e no seu país sede, no entanto, quando ocorre a interação do conhecimento e das capacidades entre as cadeias, parte desse conhecimento pode ser apropriado pelas demais firmas, o que lhes permitem realizar um upgrading técnico-produtivo, ampliando sua competitividade em setores mais dinâmicos.

Portanto, a posição na hierarquia do valor adicionado da cadeia produtiva e as possibilidades de aprendizagem nas etapas do processo produtivo são fundamentais para o crescimento dos países do ponto de vista tecnológico e estrutural. "Com efeito, a separação do processo produtivo favorece especialmente os detentores dos ativos intangíveis ( $\mathrm{P} \& \mathrm{D}$, desenho e concepção, marca, comercialização) na apropriação do valor adicionado, restando para as atividades padronizadas e de menor qualificação uma fração reduzida e submetida a elevada competição" (Medeiros, 2010, p. 10).

Dessa forma, a participação de um país no processo produtivo fragmentado ou em cadeias internacionais de valor não the assegura necessariamente ganhos dinâmicos advindos de sua especialização produtiva, pois nem todos os países in-

montagem de produtos para exportação (automóveis e produtos eletroeletrônicos). Estas maquilas se baseiam em elevados incentivos fiscais, nos diferenciais de custo de mão de obra e na forte dependência do mercado consumidor norte-americano, com baixa capacidade de difusão para o conjunto da indústria mexicana (Capdvielle et al., 1996).

\footnotetext{
${ }^{5}$ Outra abordagem sobre as cadeias globais de valor com enfoque nas estratégias no nível da firma pode ser vista em Ernst (2005) e Berger (2006).
} 
tegrantes das cadeias internacionais de valor conseguem extrair benefícios similares, dadas as diferenças de posicionamento dentro de uma mesma cadeia. Esses benefícios dependerão principalmente da capacidade de apropriabilidade e cumulatividade das firmas nacionais na implementação de determinado estágio do processo produtivo, ligada ao aprendizado e à mudança tecnológica. $\mathrm{O}$ comércio exterior de partes e componentes é uma boa medida para distinguir a posição em determinada cadeia de valor: um produto exportado de alto valor pode ter sido apenas montado nos limites do país a partir de produtos intermediários importados de outros países. Assim, o aumento das importações de peças e componentes indica que as atividades de montagem no país são maiores, enquanto um aumento em suas exportações sugere um aumento da importância do país no abastecimento de determinada cadeia global de valor (Gereffi, 1994; Ernsts e Kim, 2001).

\section{PANORAMA GERAL DO COMÉRCIO DE PRODUTOS DE ALTA TECNOLOGIA DO MERCOSUL}

As transformações da economia global observadas nas últimas décadas provocaram uma polarização mundial na qual de um lado há alguns países, como a China, e regiões, como o Leste Asiático, que conseguiram se beneficiar de tais mudanças e obter saltos econômicos, passando a concentrar a produção manufatureira. No outro extremo há um grupo formado por países desenvolvidos como os Estados Unidos e os da União Europeia, além de emergentes como os países do Mercosul, que passam atualmente por um processo de arrefecimento da produção de manufaturas e, em alguns casos, por uma desindustrialização de suas economias.

Diversos trabalhos sugerem que o sucesso asiático em termos de desempenho exportador e de crescimento econômico está relacionado à sua especialização produtiva e comercial, na qual a integração regional contribuiu de forma decisiva. $\mathrm{O}$ que se percebe nas economias asiáticas é um movimento de aprendizagem tecnológica e de integração regional, por meio de um processo de absorção e transferência de tecnologias que têm permitido a tais países avançarem em áreas de tecnologia mais avançada, como maquinários elétricos, componentes e equipamentos de informática (Lemoine e Ünal-Kesenci, 2004).

Apesar do crescimento do comércio exterior dos países da América Latina nos anos recentes, estudos de comércio demonstram que tais economias ainda apresentam um padrão de especialização fortemente intensivo em produtos primários e de manufaturas intensivas em recursos naturais. Isso, por sua vez, implica uma baixa integração dos países latino-americanos às cadeias internacionais de valor, uma vez que tais indústrias são caracterizadas por processos contínuos de produção, pouco sujeitas à fragmentação, e sua competitividade está muito atrelada à noção de vantagens comparativas.

Para verificar a atual inserção comercial dos países do Mercosul em setores de alta tecnologia, procurou-se analisar a evolução tanto das exportações quanto das 
importações, bem como do saldo comercial e da participação relativa no total exportado por país e de cada país no conjunto do bloco.

Cabe dizer, foram selecionadas todas as categorias e subcategorias ${ }^{6}$ que abrangem produtos finais, peças e componentes, e semiacabados de manufaturas de alta tecnologia, de acordo com a classificação de Lall (2000). Este autor agregou os setores de comércio, a três dígitos, por classes de esforço ou intensidade tecnológica e construiu uma taxonomia baseada na tipologia de Pavitt (1984) e na classificação elaborada pela OCDE (1994). A partir de uma interação entre elas e de um avanço ${ }^{7}$ em relação a elas, o autor classificou os setores com diferentes níveis de complexidade tecnológica e os ordenou em cinco distintas categorias: produtos primários, manufaturas baseadas em recursos, baixa tecnologia, média tecnologia e alta tecnologia. Essa última, objeto do presente artigo, engloba produtos desenvolvidos através de tecnologias avançadas e elevados investimentos em P\&D, com enfoque no design. Ou seja, tais produtos requerem sofisticadas infraestruturas tecnológicas, elevados níveis de especialização, mão de obra especializada e mecanismos de interação frequente entre as firmas e entre as firmas e as universidades/ institutos de pesquisa.

Para construir sua taxonomia, Lall (2000) utilizou o sistema de Classificação Padrão do Comércio Internacional (SITC) Revisão 2, pois a análise a que se propunha era composta de um horizonte temporal muito grande e a Revisão 2 compreende dados desde o início dos anos 1980, ao contrário da Revisão 3, que é desenvolvida em níveis mais desagregados, mas só apresenta dados a partir dos anos 1990. O período de análise proposto nesse estudo é de 1991 a 2011, desde o ano da formação do Mercosul até o ano em que há disponibilidade de dados, ou seja, é um horizonte de tempo, em sua maioria, possível de ser visualizado na SITC Revisão 3. Sendo assim, e de acordo com os propósitos do artigo, optou-se por utilizar tal revisão, pois os dados para alguns produtos industrializados complexos, sobretudo da categoria 7 e 8 do COMTRADE, incluem subcategorias até cinco dígitos para fins de comércio exterior de peças e componentes desses produtos, o que não era discriminado na Revisão 2. Dessa forma, foi necessário compatibilizar a classificação realizada por Lall (2000) para o grupo "Manufaturas de alta tecnologia” da Revisão 2 para Revisão 3.

Optou-se ainda por verificar a inserção comercial do Mercosul comparativamente às outras economias, como Estados Unidos, China e Japão, e áreas econômicas como a União Europeia. Nota-se, através do Gráfico 1, que o comércio in-

\footnotetext{
${ }^{6}$ Algumas subcategorias da SITC são mais subdivididas que outras, portanto existem grupos com códigos de três dígitos e grupos com códigos de cinco dígitos. Entretanto, não se incluiu na análise subgrupos com mais dígitos quando se incluiu o código principal a três dígitos, ou seja elimina-se o problema de dupla contagem.

${ }^{7}$ Possui um tratamento de agregação dos dados mais minucioso com relação ao esforço inovativo, excluindo produtos de baixa e média intensidade tecnológica do grupo de alta, como por exemplo de tintas e vernizes, que, embora sejam parte do setor de químicos, não envolvem grande esforço inovativo como os produtos farmacêuticos, também do grupo de químicos.
} 
ternacional de produtos de alta tecnologia aumentou vigorosamente nos últimos 20 anos. Em 1991, as exportações mundiais de tais produtos estavam em torno de US\$ 480 bilhões e, apesar da crise de 2008, que reduziu seu patamar, alcançou em 2011 um total de aproximadamente US\$ 2.700 trilhões. Ou seja, de 1991 para 2000 as exportações mundiais de manufaturas de alta tecnologia cresceram $82 \%$. Da mesma forma, as importações de tais produtos cresceram $84 \%$ no mesmo período, conforme gráfico 2 .

Gráfico 1: Exportações de manufaturas de alta tecnologia (em US\$ bilhões)

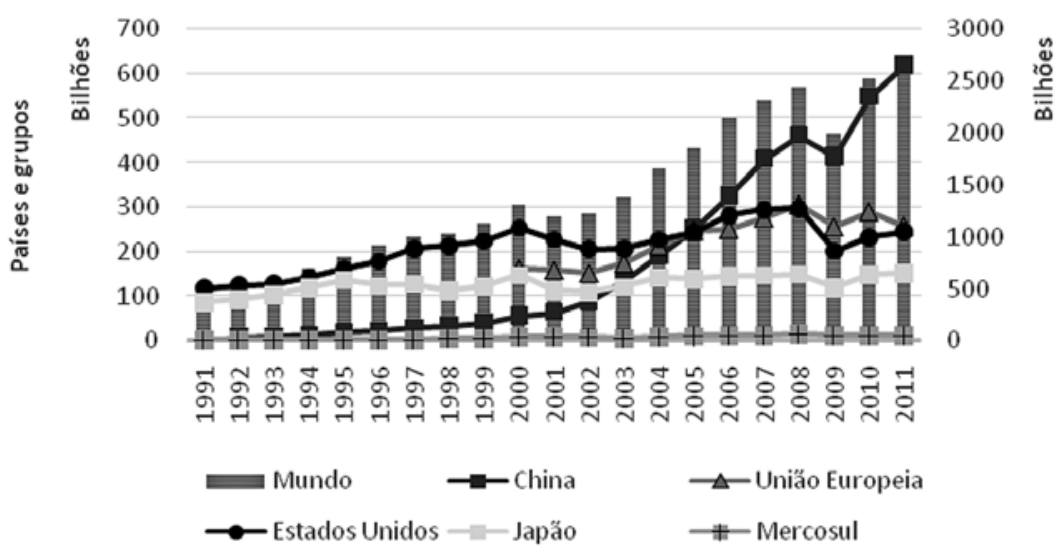

Fonte: Elaboração própria a partir de dados do COMTRADE (2012).

Gráfico 2: Importações de manufaturas de alta tecnologia (em US\$ bilhões)

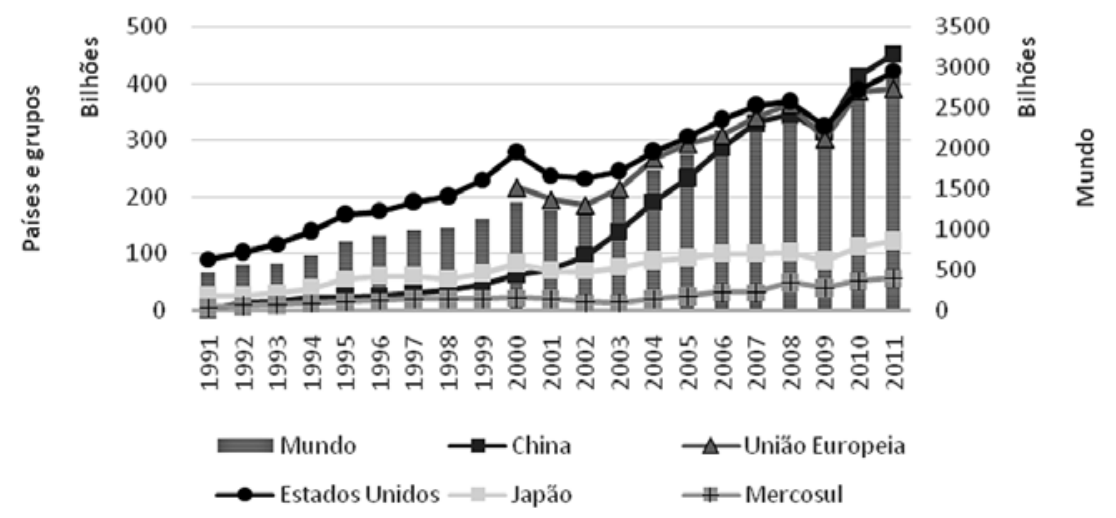

Fonte: Elaboração própria a partir de dados do COMTRADE (2012).

Ao analisar os gráficos, nota-se que ainda mais relevante foi a transformação ocorrida na estrutura do comércio internacional ao longo dos 20 anos. De acordo com relatório da UNCTAD (2002), as exportações de tais produtos cresceram mais 
em países em desenvolvimento do que nos países desenvolvidos, ao contrário dos pressupostos do modelo $\mathrm{H}-\mathrm{O}$ de comércio internacional; contudo, esta alteração nos fluxos de comércio apresenta-se concentrada na região asiática, devido ao progresso tecnológico, à transferência internacional de tecnologia e aos investimentos diretos externos (IDE) verificados na região. Percebe-se claramente um movimento de tendência de polarização do comércio de produtos de alta tecnologia, com alguns países ganhando destaque em detrimento da participação de outros. Paralelo a isso, verifica-se uma redução do market share de alguns países e um incremento da participação no total importado por eles.

Esse é o caso dos Estados Unidos, que mais do que duplicou suas exportações de 1991 para 2011 e, no entanto, reduziu seu market share em 16\%. Além disso, importava cerca de US\$ 88 bilhões no primeiro ano e passou a importar US\$ 421 bilhões no último ano do período analisado. Apesar desse aumento do componente importado nos setores de alta tecnologia, os Estados Unidos apresentaram queda na participação do total importado pelo mundo nesse conjunto de setores (de $19 \%$ para $16 \%$ ), fruto do processo de fragmentação produtiva.

No mesmo sentido, segue o fluxo de exportações e importações da União Europeia, cujo market share caiu de $12 \%$ em 2000 para $9 \%$ em 2011 e a parcela de conteúdo importado caiu de $16 \%$ para $13 \%$. No entanto, o grupo de países ainda apresenta saldos comerciais melhores que os da economia americana, com um total exportado de US\$ 256 bilhões e importado de US\$ 390 bilhões em 2011. Apesar de certa estabilidade do fluxo de exportações ao longo do período analisado, o Japão assistiu sua parcela de mercado cair de $18 \%$ para $5 \%$ e sua parcela de conteúdo importado de produtos de alta tecnologia declinar de 5,35\% para $4,24 \%$, mesmo com um aumento das importações de US\$ 25 bilhões para US\$ 122 bilhões.

Do outro lado dessa nova configuração do comércio de produtos de alta tecnologia destaca-se a China, cujo volume exportado e importado aumentou progressivamente, exceto pela queda em 2009, fruto da crise internacional de 2008, durante todo o período analisado. Em $1992^{\circ}$ a China não detinha $1 \%$ do total de manufaturas de alta tecnologia exportadas no mundo, 20 anos depois passou a ter o domínio de $16 \%$ do mercado mundial de tais produtos, exportando cerca de US\$ 619 bilhões e importando US $\$ 453$ milhões em 2011, valores $99 \%$ e $97 \%$ maiores, respectivamente, do que em 1992.

Cabe ressaltar, tais evidências empíricas explicitadas nos Gráficos 1 e 2 se dão a partir da análise de estatísticas de comércio tradicionais - valores brutos de exportação e importação, e de classificações usuais - segundo conteúdo tecnológico, ou seja, baseiam-se na noção tradicional de especialização horizontal, em que os países comercializam bens que são produzidos do início ao fim em apenas um país. Portanto, elevações na participação das exportações de setores de alta tecnologia da China em relação aos Estados Unidos e Japão podem ser apenas uma espécie de "ilusão estatística", já que não necessariamente a China domina a base

\footnotetext{
${ }^{8}$ Não há dados disponíveis para a China em 1991, dentro da SITC Revisão 3.
} 
tecnológica do processo produtivo de tais setores (Lall, 2000). Sendo assim, a análise desses gráficos não nos permite afirmar em que medida os países selecionados estão participando efetivamente dos estratos superiores das cadeias produtivas de manufaturas de alta tecnologia ou apenas realizando a montagem final dos produtos; principalmente no caso da China, que tradicionalmente tende a se especializar em setores intensivos em trabalho dentro das indústrias intensivas em tecnologia.

No entanto, ao recorrer a uma vasta literatura sobre o papel da China no comércio internacional ${ }^{9}$, é possível verificar que seu recente resultado positivo está fortemente associado a uma transformação do padrão de especialização da China (que, por um lado, tem incorporado setores de maior valor agregado à sua pauta exportadora, e, por outro, tem assumido uma posição cada vez mais privilegiada na fragmentação dos processos de produção): inserção em níveis mais a jusante das Cadeias Globais de Valor em indústrias de alta tecnologia (Lemoine e Ünal-Kesenci, 2004). Tal movimento iniciou-se com a fragmentação dos processos produtivos de países desenvolvidos como o Japão, os Estados Unidos e a União Europeia que se dirigiram para a China e outros países asiáticos em busca de mão de obra barata para a fase de montagem do processo produtivo. Por muitos anos, empresas multinacionais exportaram partes e componentes para a China, que atuava como mera montadora e reexportadora. No entanto, a China foi incorporando tecnologia e alcançando fases mais a jusante do processo produtivo através de um conjunto de políticas industriais de longo prazo, como planos de desenvolvimento tecnológico e científico, de esforços inovativos e de qualificação da mão de obra que permitiram um aumento do seu market share na produção de bens intermediários de setores de alta tecnologia (IEDI, 2011 e Nonnemberg; Mesentier, 2012).

Como já era esperado, o desempenho do Mercosul no comércio mundial de tais setores, quando comparado às demais economias, ainda é muito incipiente. As parcelas de mercado de todas as economias do bloco em conjunto não alcançam $1 \%$, durante todo o período analisado, do total de manufaturas de alta tecnologia exportado pelo mundo. Entretanto, nota-se que as exportações de produtos de alta tecnologia cresceram em torno de $88 \%$ de 1991 para 2011, de aproximadamente US\$ 1 bilhão para US\$ 11 bilhões. Da mesma maneira, as importações de tais produtos cresceram $92 \%$ ao final do período, cerca de US\$ 4 bilhões para US\$ 55 bilhões. Embora a magnitude dos valores em 2011 seja ainda muito inferior, comparativamente às demais economias, as altas taxas de crescimento das exportações e importações no período refletem que os países do bloco estão de alguma maneira buscando se inserir em mercados mais dinâmicos e em cadeias internacionais de valor. Ademais, tais taxas de crescimento estão acima das taxas de crescimento do comércio mundial de manufaturas de alta tecnologia, demonstrando, ainda que de forma modesta, o potencial de tais economias para a produção de mais produtos de elevado valor agregado.

\footnotetext{
${ }^{9}$ Lemoine e Ünal-Kesenci (2004); Schott (2006); Xu e Lu (2010); Nonnemberg e Mesentier (2012), dentre outros.
} 
O Gráfico 3 ilustra a evolução do comércio de tais setores dos países do bloco durante todo o período pós-Tratado de Assunção.

Gráfico 3: Comércio total de manufaturas de alta tecnologia dos países do Mercosul (em US\$ bilhões)

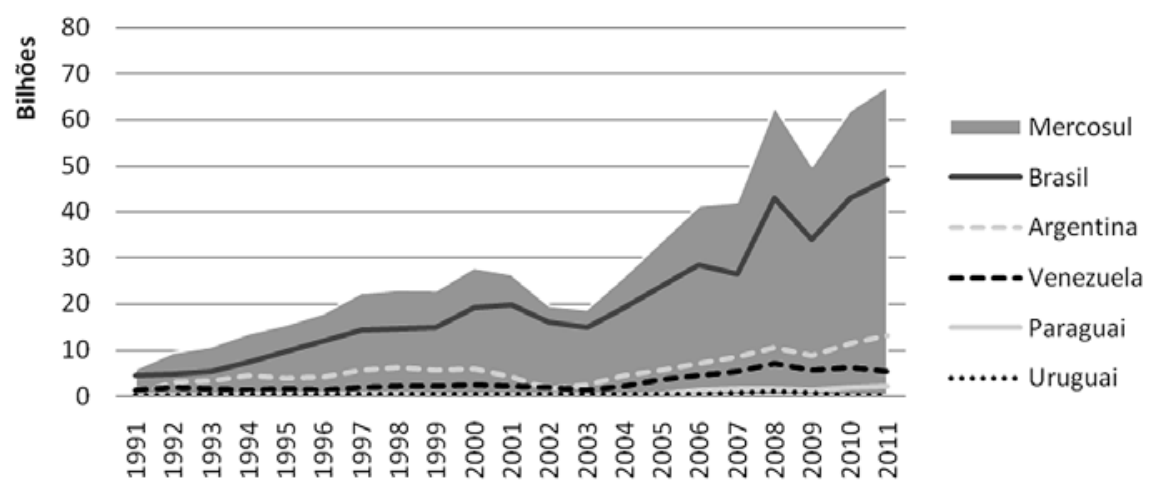

Fonte: Elaboração própria a partir de dados do COMTRADE (2012).

Brasil e Argentina são os países com maiores fluxos de comércio de manufaturas de alta tecnologia. O Brasil apresenta uma trajetória crescente no comércio total do conjunto de setores que compõem a indústria de alta tecnologia, na quase totalidade do período, alcançando em $201170 \%$ do total comercializado pelos países do bloco. Fica claro que essa elevada participação determina a própria configuração do desempenho do bloco, que possui uma tendência estreitamente ligada ao comportamento dos fluxos de comércio do Brasil. No entanto, é importante salientar uma questão de caráter macroeconômico. O Brasil possui PIB equivalente a mais de duas vezes o argentino, ou mais de cinco vezes o venezuelano, e, portanto, é a economia do bloco com maior potencial de expansão, o que pode significar um efeito positivo para uma região integrada. Porém, apesar de ser a maior economia do bloco e da América Latina, ainda apresenta taxas de crescimento do PIB inferiores à média do conjunto de países latino-americanos, o que limita estruturalmente seu papel de articulador e propulsor do desenvolvimento de setores com alto teor tecnológico entre as economias da região.

A Argentina, segunda economia com maior peso no bloco, apresentou $19 \%$ da participação no somatório das exportações e importações de manufaturas de alta tecnologia do Mercosul em 2011. Entretanto, percebe-se que os problemas econômicos enfrentados pelo país, sobretudo em 2001 e 2002, reduziram tanto a parcela importada quanto a exportada de manufaturas com maior valor agregado. Dentre os demais países destaca-se a Venezuela, que embora tenha diminuído os fluxos de comércio em tais setores ao longo da década 1990, relativamente aos demais que à época já eram membros do bloco, tem apresentado uma trajetória ascendente, com taxa de crescimento de cerca de $80 \%$ de 2003 a 2011. Os países andinos, Uruguai e Paraguai, em contrapartida, não somente têm um peso reduzido no co- 
mércio total dos produtos de alta tecnologia do Mercosul, como também incorrem em déficits relevantes nesses setores como proporção do seu PIB. Vale dizer, no caso do Paraguai, que as exportações de manufaturas de alta tecnologia refletem as reexportações de produtos eletrônicos e elétricos, dentre outros.

O Gráfico 4 sintetiza os dados acerca do saldo comercial dos países do Mercosul relativamente ao conjunto de países do bloco. Fica claro que os países maiores desfrutam de um déficit comercial maior no comércio total de manufaturas de alta tecnologia com relação aos menores que, em compensação, apresentam parcela reduzida do comércio total. Nota-se também uma elevação dos déficits, sobretudo a partir de 2002, ano em que as exportações da China de manufaturas de alta tecnologia apresentam um expressivo e contínuo aumento, fruto de sua entrada na Organização Mundial do Comércio (OMC) nesse mesmo ano. Esta ascensão chinesa tem impactos sobre o comércio do bloco, na medida em que a China é um parceiro externo relevante para a região, e que pode estar afetando negativamente o comércio dos países do Mercosul intra e extrabloco, especialmente de produtos manufaturados. Além disso, em função de sua localização geográfica e de sua infraestrutura precária, os países do Mercosul não se inseriram de forma significativa na produção compartilhada global, com processos de integração comercial fortemente assimétricos, na medida em que o conteúdo importado das exportações e a ausência de políticas tecnológicas levaram a uma forte polarização de sua estrutura produtiva com baixo dinamismo econômico (UNCTAD, 2002).

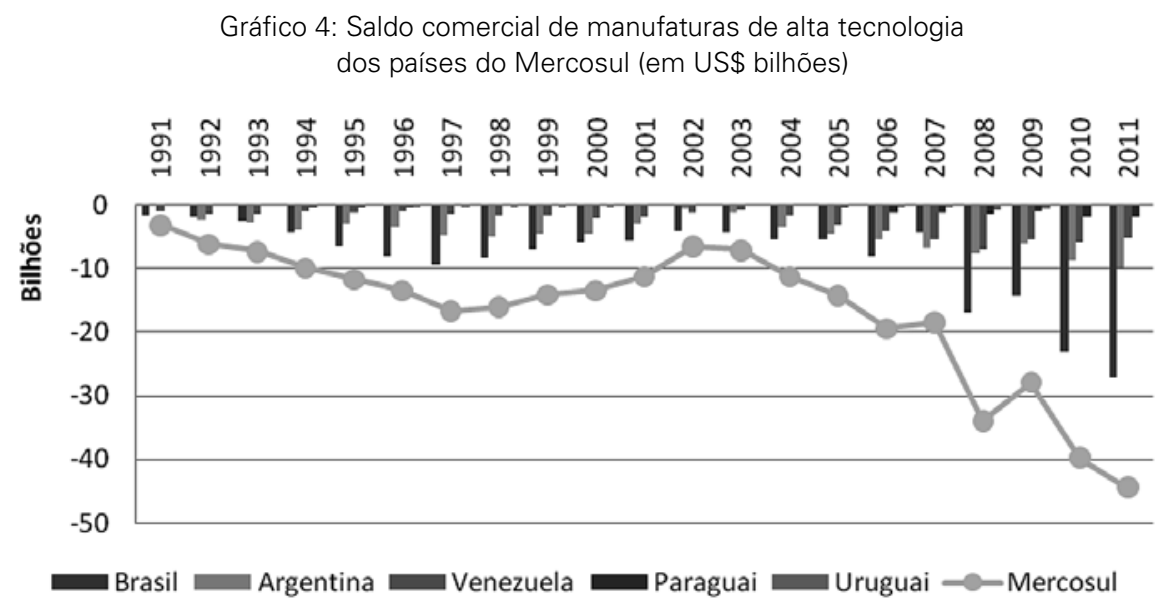

Fonte: Elaboração própria a partir de dados do COMTRADE (2012).

A literatura econômica aponta que o aumento do comércio de produtos de alta tecnologia nos últimos anos se deu principalmente pela reorganização da produção global e pela integração comercial e produtiva das economias. Para sobreviver a essas mudanças na dinâmica da economia global, os países da América Latina têm se organizado politicamente em prol de movimentos de integração, na medida em que não têm escala de produção para ganhar competitividade isolada- 
mente como uma economia industrial moderna. O estabelecimento do Mercosul, embora não tenha adotado políticas deliberadas de promoção industrial do bloco, acabou por incentivar um avanço no processo de integração das economias latino-americanas; resta aqui saber em que medida permitiu a formação ou intensificação das relações comerciais e/ou produtivas entre as economias do bloco, em setores produtores de manufaturas de alta tecnologia.

A partir de uma análise mais detalhada dos fluxos de exportações das manufaturas de alta tecnologia intra e extrabloco é possível verificar que, do total exportado pelo Mercosul em 1992, aproximadamente 18\% foram para as próprias economias do bloco; essa parcela aumentou significativamente em 1996 para $33 \%$ e depois caiu abruptamente em 2001 para 13\%. Nos últimos anos analisados, tal patamar voltou ao nível de $30 \%$, configurando maior integração comercial do bloco em setores dinâmicos e demonstrando o grande peso das exportações de manufaturas de alta tecnologia sobre o comércio intrarregional. Dentre as economias do bloco, o Paraguai é aquela para quem o bloco tem maior importância para escoamento de tais produtos (em 1992, 69\% das exportações eram destinadas ao Mercado Comum do Sul; já em 2011, esse percentual subiu para 76\%). Isso e devido ao seu papel de reexportador de produtos elétricos e eletrônicos, dentre outros. Pelo contrário, a Venezuela é a economia menos integrada em termos de comércio nesses setores, com apenas $1 \%$ de suas exportações sendo destinadas ao Mercosul em 2011. Tal fato era esperado, na medida em que a Venezuela só tem se beneficiado das tarifas e dos benefícios do bloco recentemente, com a sua adesão em 2012; por outro lado, mostra as potencialidades que a entrada desse país pode permitir em termos de fluxos comerciais para as demais economias do bloco.

Outra constatação importante da análise do comércio bilateral desses países diz respeito à forte interdependência entre as duas economias com maior base industrial do bloco: em todos os anos mais de 50\% das exportações brasileiras de produtos de alta tecnologia eram destinadas unicamente para a Argentina; da mesma maneira, o principal parceiro da Argentina dentro do Mercosul é o Brasil. Isso demonstra que, ainda que a integração regional seja muito pequena quando comparada com outras regiões, como a asiática, alguns fatores como os menores custos de transação - devido à proximidade geográfica, etc. —, a atuação regional de empresas multinacionais na região e as políticas de incentivo a complementaridade produtiva podem estar fomentando uma articulação produtiva entre os países vizinhos.

Quanto à composição das exportações e importações da indústria de manufaturas de alta tecnologia do Mercosul em 2011 é possível perceber um padrão em sua configuração, no qual os setores que mais se destacaram na pauta de exportações são os mesmos que mais pesaram na pauta de importações, o que pode configurar um padrão de especialização em tais setores da indústria. O setor 764 - equipamentos de telecomunicação - é o que apresenta a maior participação relativa tanto nas exportações ( $42 \%$ do total da indústria) quanto nas importações $(23 \%)$ de setores de alta tecnologia. Isso demonstra o grande volume de partes e acessórios transacionados pelo bloco, na medida em que o setor 764, quando desagregado a quatro e cinco dígitos, constitui-se inteiramente de componentes destinados à produção de 
produtos finais da divisão 76 - aparelhos e equipamentos de telecomunicação, de gravação e reprodução de som, basicamente rádio, TV e telefones celulares.

Em seguida aparece o setor 776 - transistores, válvulas, etc., com uma parcela de $17 \%$ das exportações e $11 \%$ das importações da indústria. Tal setor também é formado por um conjunto de dispositivos, transistores, válvulas e circuitos que constituem partes do processo produtivo de produtos finais da divisão a dois dígitos - 76, sobretudo de televisões. Somente esses dois setores a três dígitos, 764 e 776, representam maior peso sobre a pauta exportadora em comparação com a pauta importadora da indústria de alta tecnologia — todos os demais têm maior participação sobre as importações da indústria -, o que pode significar uma especialização dos países do Mercosul nos primeiros. O setor 752 - máquinas automáticas de processamento de dados e suas unidades - é o terceiro com maior peso, tanto nas exportações quanto nas importações, com $9 \%$ e $10 \%$ de participação, respectivamente.

Entretanto, quando avaliado o saldo comercial do conjunto de países do Mercosul, em cada um dos setores que compõem o grupo de manufaturas de alta tecnologia, o resultado dos setores 776 e 764 são os piores na geração de saldos. Durante todo o período, ambos os setores contribuíram negativamente para o saldo da balança comercial. O volume de componentes importados para a produção de televisões, rádios e telefones (764) foi tão superior ao volume exportado desses mesmos componentes, que denota um saldo negativo de mais de US\$ 12 bilhões em 2011. Da mesma forma, o conjunto de peças e acessórios que compõe o setor 776 apresentou um saldo negativo de US\$ 5 bilhões, sendo que ambos apresentam uma trajetória crescente a partir de 2002, demonstrando um possível impacto negativo do "Efeito China" sobre o desempenho desses setores. Além disso, tal déficit de partes e componentes dos setores de alta tecnologia reflete uma produção inserida ativamente em cadeias globais de valor, com o conjunto de países do Mercosul atuando como compradores de partes intermediárias do processo de produção de produtos finais, ou seja, sugere um caráter montador de bens finais a partir de bens importados de alta tecnologia.

O setor que melhor contribuiu para a geração de saldos positivos para a indústria de manufaturas de alta tecnologia do Mercosul foi o 792 - aeronaves e equipamentos associados. Desde 1999, esse foi o único setor que apresentou saldos positivos sustentáveis até 2011 , configurando uma inserção positiva do grupo no mercado internacional de aeronaves. No entanto, tal setor engloba um conjunto de produtos finais como aviões, helicópteros e outras aeronaves e uma série de partes e componentes destinados a tal setor, o que sugere a necessidade de uma avaliação do valor adicionado doméstico de tal categoria. É preciso também destacar que esse desempenho do Mercosul em termos de competitividade do setor 792 reflete, em boa medida, o desempenho do Brasil, dado pela grande participação do país no total comercializado pelo bloco ${ }^{10}$.

${ }^{10}$ Sabe-se que ao avaliar de forma agregada o desempenho de todos os países do Mercosul em conjunto 


\section{EVOLUÇÃO DO VALOR DOMÉSTICO ADICIONADO DO COMÉRCIO EXTERIOR DE PRODUTOS DE ALTA TECNOLOGIA DO MERCOSUL}

Uma vasta literatura tem apontado a relevância de novas estatísticas de comércio complementares, quando o objeto de estudo são setores com processos produtivos fragmentados e inseridos em cadeias globais de valor. Isso por que, nesse caso, fluxos brutos de exportações podem ser enganosos e dar a falsa percepção de que os países têm atingido uma competitividade elevada em determinados setores de alto valor agregado, enquanto os mesmos continuam incorporando durante o processo produtivo uma série de insumos intermediários provenientes do exterior, o que torna difícil identificar a real contribuição da exportação para os saldos das economias ${ }^{11}$.

Diante disso, a Organização Mundial do Comércio - OMC, em parceria com o Instituto de Economias em Desenvolvimento (IDE-JETRO), passaram a aprimorar os instrumentos metodológicos de análise de comércio a partir da construção de um indicador de valor adicionado para o comércio (Trade in Value Added TIDA $)^{12}$. Esse indicador, no entanto, está disponível para um conjunto restrito de países e anos. No mesmo sentido, Nonnenberg e Mesentier (2012) construíram um indicador de valor adicionado para analisar o crescimento recente da indústria de alta tecnologia da China por meio de dados de comércio. Tais autores adotaram como uma proxy simples, aproximada do indicador de valor adicionado, a diferença entre exportações de setores de alta tecnologia e importações de partes e componentes de tais setores.

A partir das constatações da seção anterior e do indicador construído por Nonnenberg e Mesentier (2012), analisar-se-á o valor adicionado no comércio de algumas das principais categorias identificadas na pauta de alta tecnologia do conjunto de países que compõem o Mercosul. Portanto, será construído uma pro$x y$ do valor adicionado (VA), que consiste na diferença entre produtos finais e suas principais partes e componentes, identificadas via dados disponíveis no COMTRADE. De maneira a permitir uma visão mais completa de cada categoria, serão verificadas as divisões de comércio a dois dígitos e todos os dados a quatro ou a cinco

embute-se um viés dado pelo peso que os fluxos de comércio do Brasil têm sobre o total comercializado pelo bloco.

${ }^{11}$ Dedrick et al. (2010) realizaram um estudo de caso sobre a produção do iPod da Apple na China que ilustra claramente essa questão. Eles mostraram que dos US\$144, preço final resultante do processo fabril de uma unidade do produto na China, menos de $10 \%$ contribui para o valor adicionado chinês, com cerca de US\$ 100 equivalendo a partes e componentes importados do Japão, Estados Unidos e Coreia. Vários outros estudos apontam como um bem exportado pode exigir um grande volume de insumos intermediários de fabricantes nacionais que, por sua vez, exigem significativas importações intermediárias utilizadas na produção, deixando apenas benefícios marginais para as economias exportadoras e déficits em termos de valor acrescentado.

${ }^{12}$ World Trade Organization (WTO); Institute of Developing Economies (IDE-JETRO). Trade patterns and global value chains in East Asia. Geneva: WTO, 2011. 
dígitos (produtos finais e partes/componentes) serão apresentados como parcela do total exportado pela divisão a dois dígitos do SITC, Revisão $3^{13}$.

Um dos setores com maior peso sobre a composição das exportações e importações dos países do Mercosul foi o 764 - equipamentos de telecomunicação que está incluído na divisão a dois dígitos 76, composta de equipamentos e aparelhos de telecomunicação, de gravação e reprodução de som. Tal categoria, quando desagregada, pode ser dividida em quatro grandes grupos que equivalem aos produtos finais da divisão. O primeiro compreende os aparelhos de TV e rádio e telefones celulares e é o resultado do somatório de três categorias a três dígitos, são elas: 761 - aparelhos receptores de televisão, incluindo monitores e projetores de vídeo, 762 - aparelhos receptores de radiodifusão e 7643 - telefones celulares. Os outros grupos classificados como produtos finais são: 763 - gravadores e Reprodutores de TV e som; 7641 - aparelhos telefônicos, exceto celulares ${ }^{14}$; e 7642 - microfones e Alto-falantes. As partes e componentes destinadas aos produtos finais da divisão 76 foram identificadas como: 7761 — tubos de imagem de televisão, catódicos; 7762 — outras válvulas eletrônicas e tubos — incluindo os tubos de câmara de televisão ${ }^{15}$; e 76493 - partes e acessórios reconhecíveis como exclusiva ou principalmente destinados aos aparelhos da divisão 76: como aparelhos e equipamentos dos grupos 761 e 762 e subgrupos 7643 e 7648).

A partir do Gráfico 5 é possível visualizar claramente que os países do Mercosul não são ainda exportadores líquidos de equipamentos de telecomunicação, gravação e reprodução de som. Durante o período de análise, o Mercosul produziu poucos produtos finais para exportação e ao mesmo tempo aumentou o conteúdo importado de partes e componentes para a produção desses produtos ao longo de todo o período. Percebe-se que o setor com o melhor resultado em termos de VA foi o de "aparelhos de TV e rádio e telefones celulares", que apresentou um saldo positivo entre 2001 e 2003. Aliás, esse foi um período, até 2009, no qual o Mercosul apresentou uma melhora do VA em todos os produtos que compõem a categoria 76. Tal resultado nesse período pode estar relacionado à maturação dos IDE direcionados ao setor no período de privatizações no Brasil. De acordo com Sarti e Laplane (2002), em 1997 os setores de Informática e Equipamentos de Teleco-

\footnotetext{
${ }^{13}$ Vale dizer que tal indicador também apresenta limitações no fornecimento de uma imagem completa do comércio internacional quando, por exemplo, o processo de fragmentação do processo de produção ocorre dentro de uma empresa multinacional, na medida em que os excedentes do valor acrescentado podem ser repatriados para a matriz controladora em outro país, a fim de repartir lucros ou para pagamentos de direitos de propriedade intelectual.

${ }^{14}$ Apesar de aparelhos de telefone serem classificados em outra parte, na posição 76411 , telefones celulares devem ser analisados em conjunto com receptores de rádio e TV, pois as peças de ambos os grupos são incluídas na rubrica 76493 e não podem ser desmembrados.

${ }^{15}$ Fica claro que o setor de alta tecnologia 776 - transistores, válvulas, etc., destacado na seção anterior pelo peso que possui no total exportado e importado pelo Mercosul em 2011 é composto inteiramente por partes e componentes, dos quais a maioria é destinada à montagem de produtos finais da divisão 76. Sendo assim, esse setor também é indiretamente analisado na atual seção por meio da avaliação de suas importações pelo bloco.
} 
municação receberam elevados investimentos de novas empresas estrangeiras em grande parte associados à instalação e operação de novas plantas no país. No entanto, tais investimentos foram realizados quase exclusivamente por empresas produtoras de bens finais (montadoras) ${ }^{16}$. Não houve investimentos significativos de produtores de insumos e componentes para os bens finais. Cabe denotar uma reversão desse processo, com uma redução do valor adicionado de tais categorias como parcela da divisão 76, a partir de 2010, alcançando níveis bastante elevados de importação de partes e componentes.

Gráfico 5: Valor doméstico adicionado, divisão 76, aparelhos e equipamentos de telecomunicação (como \% das exportações)

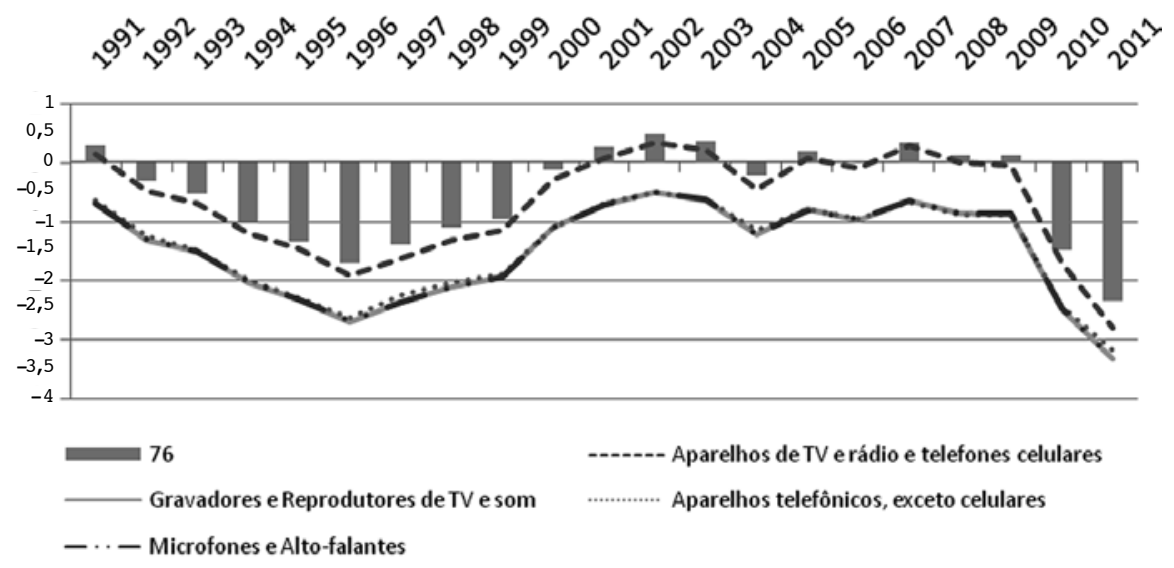

Fonte: Elaboração própria a partir de dados do COMTRADE (2012).

No mesmo sentido, Bampi et al. (2009) apontam que os países latino-americanos, sobretudo o Brasil, são apenas seguidores dos padrões ditados internacionalmente, com produtos defasados em relação ao mercado internacional de telecomunicações, ligados à baixa intensidade tecnológica dos processos de engenharia e aprimoramento de design na produção de componentes e semicondutores, o que por fim leva a uma baixa agregação de valor pelos produtos finais.

A divisão 75, máquinas para escritório e máquinas automáticas de processamento de dados, é parcelada, de acordo com a SITC, em três grupos a três dígitos, todos classificados dentro da tipologia de Lall (2000) como de alta tecnologia são eles: 751 — máquinas de escritório; 752 - máquinas automáticas de processamento de dados e suas unidades; e 759 - partes e acessórios, sobretudo para máquinas abrangidas

\footnotetext{
${ }^{16}$ É importante destacar também a promulgação da Lei no 9472 em 2000 que, procurou promover a interação com administrações de telecomunicações entre os países do Mercosul, com vistas a ampliar a competitividade dos países em tais setores, bem com outros objetivos em comum. Disponível em: http://www.planalto.gov.br/ccivil_03/leis/L9472.htm.20
} 
pelos grupos 751 e 752 . Sendo assim, as duas primeiras categorias a três dígitos referem-se a produtos finais e a última são seus principais inputs.

Gráfico 6: Valor doméstico adicionado, divisão 75, máquinas para escritório e máquinas automáticas de processamento de dados (como \% das exportações)

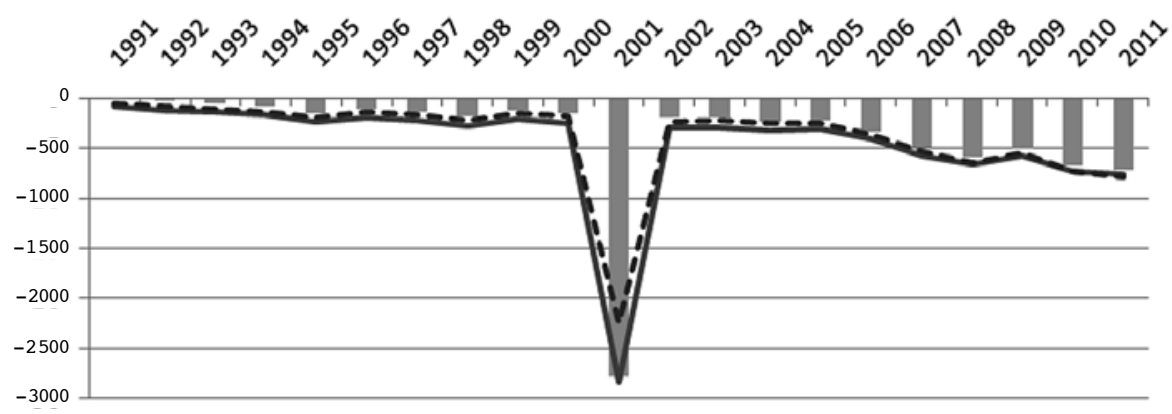

75 Máquinas de escritório - ---- Máquinas automáticas de processamento de dados

Fonte: Elaboração própria a partir de dados do COMTRADE (2012).

Percebe-se claramente que, embora os países-membros do Mercosul, especialmente Paraguai, Uruguai e Venezuela, possuam um grande volume exportado da categoria 75 , sobretudo do setor 752 (como descrito na seção anterior), ainda são muito dependentes de elementos de outras fases do processo produtivo não disponíveis em abundância na região. Sendo assim, o aumento das importações de partes e componentes ao longo do período parece denotar que os países do bloco ainda se constituem em meros montadores de máquinas para escritórios e máquinas automáticas de processamento de dados. Uma forte constatação verificada no Gráfico 6 é o ponto de inflexão em 2001, quando o valor adicionado de ambos os produtos finais caem bruscamente. Isso ocorreu nesse ano em específico não por um aumento do componente importado, que, ao contrário, caiu cerca de $10 \%$ de 2000 para 2001, mas sim por um elevado declive das exportações de produtos finais, em torno de $90 \%$ entre tais anos. É importante salientar que a maior parte do processo produtivo de máquinas automáticas para processamento de dados tem sido realizada, desde o final dos anos 1990, pela China, que começou a ampliar de maneira crescente seu market share no setor, passando de 4\% em 2000 para $43 \%$ em 2011 (COMTRADE, 2012). Tais dados podem salientar uma espécie de disputa por fatias de mercado entre a China e os países do Mercosul, na qual a primeira passa a aumentar cada vez mais o VA na divisão 75 e os demais diminuem consequentemente o VA no mesmo grupo de produtos (Nonnemberg e Mesentier, 2012).

A terceira categoria que merece uma análise mais minuciosa de sua real contribuição é o 792 - aeronaves e equipamentos associados - inserido na divisão a dois dígitos 79 , que foi desmembrada em um grande grupo formado por todos os produtos finais e outro formado por partes e componentes, ambos desagregados a quatro dígitos. Os produtos finais referem-se ao somatório das categorias 7921, 
7922, 7923, 7924 e 7925, todas caracterizadas como aeronaves, somente com especificidades distintas, por isso tal grupo agregado foi denominado "Aeronaves". $\mathrm{E}$ as principais partes e componentes destinadas a esses grupos estão descritos nos subgrupos 7928 e 7929 e nas categorias ainda mais desagregadas.

O Gráfico 7 demonstra que este é o setor com melhor desempenho em termos de valor adicionado entre 1991 e 2011. A partir de 1995, o VA do comércio do setor de aeronaves apresentou uma tendência de ascensão até 2000, quando sofreu uma inflexão e a partir de então aparece razoavelmente constante. Esse resultado parece apontar para um upgrading na CGV do setor.

Gráfico 7: Valor doméstico adicionado, divisão 79, aeronaves e equipamentos associados (como \% das exportações)

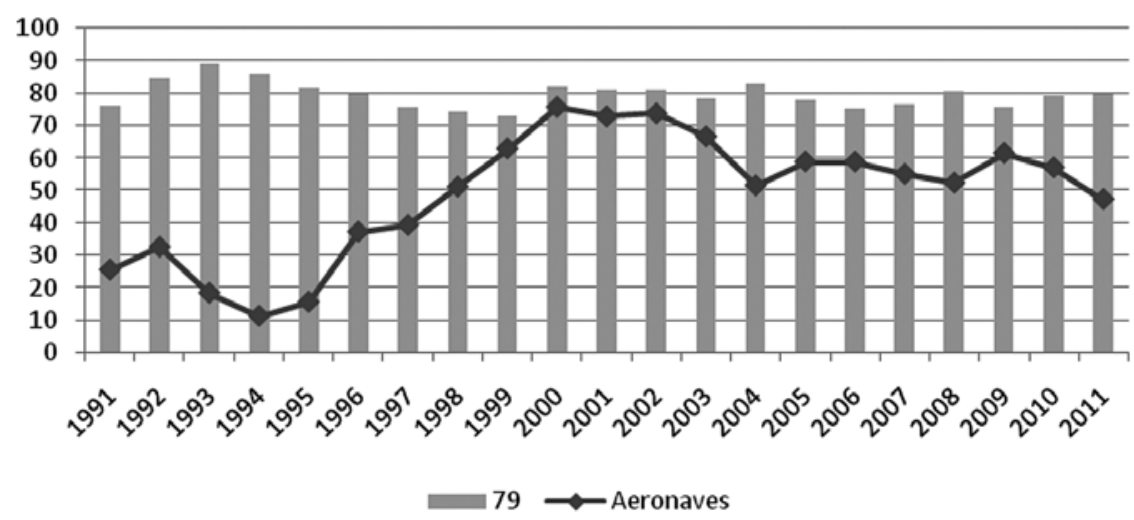

Fonte: Elaboração própria a partir de dados do COMTRADE (2012).

O caso da categoria 79 , especialmente no que tange ao grupo "Aeronaves" 792 - é emblemático e reflete o ganho de competitividade auferido pelo Brasil no período recente. É um dos casos mais salientados de desempenho competitivo obtido através do "fortalecimento do binômio empresa nacional (Embraer e seus fornecedores locais) / planejamento público (desenvolvimento tecnológico e financiamento)" (Coutinho, Hiratuka e Sabatini, 2005). A Embraer atua em segmentos específicos de mercado em três áreas: comercial, defesa e aviação executiva, e atualmente é a terceira maior fabricante de aeronaves civis, representando um caso de sucesso de entrada em um oligopólio fechado dominado por empresas norte-americanas e europeias.

Entretanto, trabalhos que avaliam dados brutos de exportação e importação apontam que a Embraer é dependente de importações de peças e componentes durante o processo produtivo de aeronaves, o que não é evidenciado pelo cálculo do VA no presente artigo. Por exemplo, de acordo com o relatório de Oliveira (2008, p. 4): “[...] embora a Embraer seja uma grande exportadora, o volume de importações é significativo. Muitos dos elos importantes da cadeia aeronáutica são provenientes de empresas instaladas no exterior, partes como: sistemas de voo, sistemas hidráulicos, turbinas, sistemas de software embarcado, material composto 
(de várias características), entre outros, são oriundos de firmas normalmente localizadas em países como EUA, Canadá e União Europeia (em especial a França)".

Goldstein (2002) aponta que desde os anos 1970 a Embraer procurou estabelecer laços de cooperação com parceiros estrangeiros, via coprodução e medidas de licenciamento; além disso, inseriu-se no processo de fragmentação da produção de aviões, importando um grande volume de peças e componentes de fabricantes mais competitivos, com os quais desenvolveu interações fortes de longo prazo, que proporcionaram vantagens competitivas à empresa na concepção e montagem das aeronaves. Por outro lado, o segmento de "Aeronaves" obteve forte investimento na capacitação de fornecedores locais reduzindo, dessa forma, a quantidade de componentes importados que influenciam negativamente no saldo da balança comercial. Ou seja, a melhoria dos saldos comerciais do segmento aeroespacial se deu, em grande parte, aos subsídios que a Embraer obtém do governo, buscando reduzir a quantidade de componentes importados durante o processo de produção das aeronaves (Goldstein, 2002). Sendo assim, os resultados do cálculo do VA podem estar indicando a consolidação desses incentivos ou podem estar superestimando a contribuição positiva sobre o saldo, já que é baseado em apenas uma parcela dos insumos utilizados para a produção de aeronaves (pertencentes à categoria 79).

\section{CONSIDERAÇÕES FINAIS}

Com base no referencial adotado, o presente artigo parte da noção de que uma inserção dinâmica dos países no comércio internacional requer a exportação de produtos tecnologicamente mais desenvolvidos. Apesar das altas taxas de crescimento da participação de manufaturas de alta tecnologia sobre o total exportado pelas economias do Mercosul, as mesmas ainda se apresentam muito distantes dos líderes desses segmentos na nova configuração internacional que tem se estabelecido nas últimas décadas. Dessa forma, ante a emergência do processo de fragmentação internacional da produção associada à formação de CGV, são necessários esforços contínuos para a construção de uma base industrial consolidada nesses países, por meio de um sólido desenvolvimento tecnológico doméstico, seja por parte de empresas nacionais, de IDE, ou de empresas transnacionais já atuantes. Por outro lado, tais resultados aqui apontados revelam a importância de um conjunto de ações estatais como políticas industriais de longo prazo, planos de desenvolvimento tecnológico e científico, de esforços inovativos e de qualificação da mão de obra que permitam às economias do bloco se inserir de forma mais dinâmica nas redes integradas de valor, aproveitando oportunidades de expansão do comércio intrarregional. Ressalta-se aqui a importância da continuidade de políticas e ações "puxadas" pelo Brasil que, como principal economia do bloco, pode, de forma mais determinante, atuar como articulador e propulsor da formação de cadeias de valor em setores com alto teor tecnológico, não só entre os países-membros do Mercosul, como em todas as economias latino-americanas.

Os dados do valor adicionado das categorias de alta tecnologia selecionadas 
sugerem que os países do Mercosul ainda estão atuando como montadores de produtos finais, na medida em que o volume das principais partes e componentes associados ampliou-se na média ao longo do período. Os dados aqui apresentados não mostram evidências fortes de que tais países estejam avançando para etapas mais a jusante das cadeias de valor nos setores de alta tecnologia. Dado o fato de os países do bloco apresentarem um padrão de especialização fortemente baseado em commodities, um upgrading nas cadeias de valor dependerá da capacidade de cada país e do bloco em conjunto de combinar as vantagens comparativas naturais da região com investimentos em tecnologia, diferenciação de produtos e diversificação de mercado.

O setor que se mostrou como uma exceção a essa configuração foi o grupo "Aeronaves", que apresentou um VA positivo ao longo de todo o período de análise. No entanto, até quanto a este setor é preciso salientar que o bom resultado não pode ser atribuído a todas as economias do bloco, já que se deve sobremaneira à empresa brasileira Embraer, cujo desempenho e transbordamentos se concentram no Brasil e na Argentina (sua parceira comercial). Além disso, dada a simplicidade de tal indicador, que engloba somente parte dos componentes utilizados no processo de produção, é possível que haja aqui uma superestimação do VA no comércio do setor de aeronaves, visto que outros trabalhos apontam o caráter deficitário da Embraer quando realizam a análise de todos os componentes que os compreendem.

Dessa forma, os resultados aqui expostos sugerem trabalhos futuros como um estudo de caso com o cálculo do índice VA para todos os insumos e produtos gerados importados e exportados no processo de produção de aeronaves pela Embraer. Do mesmo modo, são sugeridos trabalhos com ênfase em cada setor classificado como de alta intensidade tecnológica, a fim de permitir uma proxy ainda mais aproximada do indicador convencional de valor doméstico adicionado e uma análise pormenorizada das principais fontes e destinos, tanto dos produtos finais quanto das partes e componentes que possam configurar as cadeias globais de valor e os processos de fragmentação em que as economias do Mercosul estão inseridas.

Por fim, estender essa análise para a indústria de média tecnologia (automobilística, bens de capital, entre outras) permitiria compreender de forma ainda mais completa a inserção nesses fenômenos, posto que nessa indústria encontram-se setores mais integrados às cadeias produtivas - como o setor automobilístico no Mercosul.

\section{REFERÊNCIAS BIBLIOGRÁFICAS}

ATHUKORALA, P.; YAMASHITA, N. (2006) "Production fragmentation and trade integration: East Asia in a global context". The North American Journal of Economics and Finance, 17(3), 233 256.

BAMPI, S. (2008-2009) Perspectivas do investimento em eletrônica. Rio de Janeiro: UFRJ, Instituto de Economia.

BAUMANN, R. (2011) Brazilian, Chinese and Indian Exports: Is the Regional Market Really a Source of Learning? Processed. Brasília: IPEA. 
BERGER, S.(2006) Made in Monde -Les Nouvelles Frontières de l'Économie Mondiale. Paris: Ed. du Seuil.

CAPDEVIELLE, MARIO; CIMOLE, MARIO; Dutrent, Gabriela (1996) "Specialisation and technology in Mexico: a virtual pattern of development and competitiveness?" Nota de lavoro 96.09.

CEPAL - Comissão Econômica para América Latina e Caribe (2008P). Progreso técnico y cambio estructural en América Latina. Nações Unidas.

CHENERY, H. B. (1960)"Patterns of industrial growth" The American Economic Review, 50(4): 624654, p. 160.

COUTINHO, L.; HIRATUKA, C.; SABBATINI, R. (2005) “O desafio da construção de uma inserção externa dinamizadora”. In: Ana Célia Castro; Antonio Licha; Helder Queiroz Pinto Jr.; João Saboia. (Org.). Brasil em desenvolvimento, v.1: economia, tecnologia e competitividade. 1ed. Rio de Janeiro: Editora Civilização Brasileira: 271-314.

DEDRICK, J.; KRAEMER K.L.; LINDEN G. (2010) "Who profits from innovation in global value chains?: a study of the iPod and notebook PCs", Industrial and Corporate Change 19(1), 81-116.

DULLIEN, S. (2010) “Integração produtiva na União Europeia: uma perspectiva alemã: In: ALVAREZ, R.; BAUMANN, R.; WOHLERS, M. (Org.). Integração produtiva: caminhos para o Mercosul. Brasília: ABDI (Série Cadernos da Indústria ABDI, v. XVI).

ERNST, D.; KIM, L. (2001) "Global production networks, knowledge diffusion and local capability formation. A conceptual framework". East-West Center Working Papers, n. 19, Honolulu, USA, May.

FEENSTRA, R. C. (1998) "Integration of trade and disintegration of production in the global economy" Journal of Economic Perspectives, 12(4): 31-50.

FLÔRES, R. G., Jr. (2010) “A fragmentação mundial da produção e comercialização: conceitos e questões básicas. In: ALVAREZ, R.; BAUMANN, R.; WOHLERS, M. (Org.) Integração produtiva: caminhos para o Mercosul. Brasília: ABDI (Série Cadernos da Indústria ABDI, v. XVI).

GEREFFI, G. (1994) "The organization of buyer-driven global commodity chains: how US retailers shape overseas production networks. In: GEREFFI, G.; KORZENIEWICZ, M. (Eds.) Commodity chains and global capitalism. Wesport - Connecticut / USA: Praeger: 95-122.

GEREFFI, G. (1999) "International trade and industrial upgrading in the apparel commodity chain". Journal of international economics, v. 48: 37-70.

IEDI (2011) Indústria e política industrial no Brasil e em outros países. Disponível em www.iedi.org.br, 2011.

GOLDSTEIN, A. (2002) "Embraer: de campeón nacional a jugador global”. Revista de la Cepal, n 77.

HAUSMAN, R., HWANG, J., E RODRIK, D. (2007) “What you export matters”.Journal of Economic Growth. 12:.1-25.

LALL, S. (2000) "The technological structure and performance of developing country manufactured exports, 1985-1998”. Oxford Development Studies, v. 28, n. 3: 337-369.

LEMOINE, F., \& UNAL-KESENCI, D. (2004) "Assembly trade and technology transfer: The case of China". World Development, 32(5): 829-850.

MEDEIROS,C. (2010) “A. integração produtiva: a experiência asiática e algumas referencias para o Mercosul”. In: ALVAREZ, R.; BAUMANN, R.; WOHLERS, M. (Org.). Integração produtiva: caminhos para o Mercosul. Brasília: ABDI (Série Cadernos da Indústria ABDI, v. XVI).

NONNEMBERG, M. J. B.; MESENTIER, A. (2012) "Is China only assembling parts and components? The recent spurt in high tech industry". Revista Economia Contemporânea. Rio de Janeiro, v. 16, n.2:.287-315.

OLIVEIRA, L. G. (2008) Relatório Setorial Preliminar. FINEP — Financiadora de Estudos e Projetos, $\mathrm{n}^{\circ} 12$. Disponível em: (http:// www.finep.gov.br). Acesso em: 20/10/2008.

OECD (1994) Globalisation and Competitiveness: Relevant Indicators, Paris, OECD Directorate for Science, Technology and Industry, DSTI/EAS/IND/WP9(94)19.

PAVITT, K. (1984) "Sectoral patterns of technical change: towards a taxonomy and a theory". Research Policy 13: 343-373. 
RODRIK, D. (2006) “What's So Special about China's Exports?” NBER Working Paper, no. 11947. Cambridge, Massachusetts: National Bureau of Economic Research.

SARTI, F.; LAPLANE, M. F. (2002) "O investimento direto estrangeiro e a internacionalização da economia brasileira nos anos 1990". Economia e Sociedade, Campinas, v. 11, n. 1 (18):. 63-94.

SCHOTT, P. K. (2006) “The relative sophistication of Chinese exports”. NBER Working Papers. Disponível em: <http://www.nber.org/papers/w12173>. Acesso em 06/07/2013.

UNCTAD (2002) Trade and Development Report (TDR). United Nations Conference on Trade and Development, New York e Geneva.

WORLD TRADE ORGANIZATION (WTO); INSTITUTE OF DEVELOPING ECONOMIES (IDEJETRO) (2011) Trade patterns and global value chains in East Asia. Geneva: WTO.

XU, B.; LU, J. (2009) “The sophistication of exports: Is China special?” China Economic Review, ${ }^{\circ}$ 21: 482-493.

YEATS, A. (2001) "Just how big is global production sharing?” In S. W Arndt, ed., Fragmentation: New Production Patterns in the World Economy. Oxford University Press. 